\title{
The ketogenic diet is not feasible as a therapy in a CD-1 nu/nu mouse model of renal cell carcinoma with features of Stauffer's syndrome
}

\author{
Silvia Vidali ${ }^{1}$, Sepideh Aminzadeh-Gohari ${ }^{1}$, René Günther Feichtinger ${ }^{1}$, Renaud \\ Vatrinet ${ }^{2}$, Andreas Koller ${ }^{1}$, Felix Sternberg ${ }^{1}$, Tricia Rutherford ${ }^{3}$, Maura O'Donnell ${ }^{3}$, \\ Andrea Stöger-Kleiber ${ }^{3}$, Bridget Lambert ${ }^{3}$, Thomas Klaus Felder ${ }^{4}$, Wolfgang Sperl ${ }^{5}$ \\ and Barbara Kofler ${ }^{1}$ \\ ${ }^{1}$ Laura Bassi Centre of Expertise-THERAPEP, Research Program for Receptor Biochemistry and Tumor Metabolism, Department of \\ Pediatrics, Paracelsus Medical University, Salzburg, Austria \\ ${ }^{2}$ Department of Pharmacy and Biotechnology (FABIT), University of Bologna, Bologna, Italy \\ ${ }^{3}$ Clinical Nutrition, Vitaflo International Ltd, Liverpool, UK \\ ${ }^{4}$ Department of Laboratory Medicine, Paracelsus Medical University, Salzburg, Austria \\ ${ }^{5}$ Department of Pediatrics, Paracelsus Medical University, Salzburg, Austria
}

Correspondence to: Barbara Kofler, email: b.kofler@salk.at

Keywords: renal cell carcinoma, mitochondria, ketogenic diet, metabolism, Warburg effect

Received: March 10, 2017

Accepted: June 27, 2017

Published: July 17, 2017

Copyright: Vidali et al. This is an open-access article distributed under the terms of the Creative Commons Attribution License 3.0 (CC BY 3.0 ), which permits unrestricted use, distribution, and reproduction in any medium, provided the original author and source are credited.

\section{ABSTRACT}

The ketogenic diet (KD), a high-fat low-carbohydrate diet, has shown some efficacy in the treatment of certain types of tumors such as brain tumors and neuroblastoma. These tumors are characterized by the Warburg effect. Because renal cell carcinoma (RCC) presents similar energetic features as neuroblastoma, KD might also be effective in the treatment of RCC. To test this, we established xenografts with RCC 786-O cells in CD-1 nu/nu mice and then randomized them to a control diet or to KDs with different triglyceride contents. Although the KDs tended to reduce tumor growth, mouse survival was dramatically reduced due to massive weight loss. A possible explanation comes from observations of human RCC patients, who often experience secondary non-metastatic hepatic dysfunction due to secretion of high levels of inflammatory cytokines by the RCCs. Measurement of the mRNA levels of tumor necrosis factor alpha (TNFa) and interleukin-6 revealed high expression in the RCC xenografts compared to the original 786-O cells. The expression of TNFa, interleukin- 6 and C-reactive protein were all increased in the livers of tumor-bearing mice, and KD significantly boosted their expression. KDs did not cause weight loss or liver inflammation in healthy mice, suggesting that KDs are per se safe, but might be contraindicated in the treatment of RCC patients presenting with Stauffer's syndrome, because they potentially worsen the associated hepatic dysfunction.

\section{INTRODUCTION}

Kidney cancer is one of the 10 most prevalent cancers in Western countries, accounting for approximately $2-3 \%$ of adult malignancies, and renal cell carcinoma (RCC) comprises approximately $90 \%$ of all kidney cancers $[1,2]$. In patients with organ-confined disease, surgical resection is the standard therapy and has excellent outcomes [3]. Other current treatments, such as vascular endothelial growth factor (VEGF), platelet-derived growth factor (PDGF), and mammalian target of rapamycin (mTOR) antibodies and inhibitors, have been shown to increase progression-free survival, but the response is rather transient [4]. Moreover, RCC is often diagnosed at a late stage, when curative treatment is not possible. Indeed, metastatic RCC is highly resistant to treatment, with outcomes that are generally poor and a median survival after diagnosis of less than one year $[1,5]$. 
Many tumor cells display a special metabolic signature characterized by high glucose uptake and aerobic glycolysis which, even in the presence of sufficient amounts of oxygen, prevents pyruvate from being metabolized by the respiration of mitochondria, namely oxidative phosphorylation (OXPHOS) [6-9]. This metabolic switch is known as the Warburg effect $[10,11]$. In most cases this shift in metabolism is accompanied by a general down-regulation of OXPHOS activity [12-15], or it may involve deficiency of two or three of the OXPHOS complexes [16, 17], or a single defect of one of the OXPHOS subunits [18-20].

RCC also exhibits the Warburg effect. Indeed, in $\mathrm{RCC}$, an increase in glycolytic proteins and depletion of several mitochondrial enzymes has been observed $[12,21]$. Moreover, the more aggressive types of RCC are characterized by stabilization of hypoxia-inducible factor (HIF), even in normoxia, due to loss of function of the von Hippel-Lindau (VHL) gene. HIF also contributes to upregulation of many glycolytic enzymes and suppression of mitochondrial glucose oxidation $[4,22]$.

The ketogenic diet (KD) is high in fat and low in carbohydrates and protein, and it mimics starvation or prolonged exercise without restricting energy intake. It is characterized by increased ketone body levels (e.g. acetoacetate and $\beta$-hydroxybutyrate) and reduced glucose levels in the blood. Because tumor cells highly depend on glucose for energy production, limiting the glucose supply by means of KD could have anti-tumor effects. Moreover, $\mathrm{KD}$ has been reported to foster immunity, reduce both inflammation and angiogenesis, and increase apoptosis [23-25]. Finally, KD has shown good potential in enhancing the sensitivity of cancer cells to chemotherapy and in protecting normal cells from radiotherapy. Thus, KD allows cancer treatment with lower doses of chemotherapeutic agents, which might also improve patient compliance [6,26, 27].

KD was recently shown to be particularly effective in the treatment of brain tumors such as malignant glioma $[25,28]$, and was applied in several clinical studies as an adjuvant therapy for glioblastoma, astrocytoma, tumors of the gastrointestinal tract, and other advanced metastatic types of cancers [28-32]. In most cases the patients showed a stable disease or general clinical improvement, with increased progression-free survival. In a single case, there was tumor recurrence after KD suspension [24].

In preclinical studies, KD produced excellent results as an adjuvant therapy in the treatment of neuroblastoma in a murine xenograft model $[6,33]$. Neuroblastoma and RCC share a similar metabolic signature, with reduced mitochondrial DNA content and a general reduction of OXPHOS activity $[9,12]$. There is evidence that mediumchain triglycerides (MCTs) based KD's are as effective in the dietary management of intractable epilepsy as those based on long-chain triglycerides (LCTs) [34], and MCT is included in KD's as it is more rapidly metabolized and less likely to be stored in adipose tissue compared to LCTs
$[35,36]$. Based on these premises, we postulated that RCC patients might also benefit from KD therapy. Thus, to elucidate if $\mathrm{KD}$ can be used as a potential adjuvant in the treatment of RCC, we created xenografts of human RCC in immunodeficient mice and randomized the mice to a control diet group and to three $\mathrm{KD}$ groups with or without MCT enrichment.

\section{RESULTS}

\section{Human RCC xenografts have similar respiratory features as human RCC}

To ensure that human RCC xenografts of 786-O cells have similar respiratory features as human RCC, we carried out immunohistochemical (IHC) staining of the 5 OXPHOS complexes and porin (a marker of mitochondrial mass) on RCC 786-O xenograft tissue sections. The xenografts exhibited normal mitochondrial mass but significantly lower levels of OXPHOS complexes I-IV compared to normal kidney (Figure 1), consistent with previously published data on respiratory impairment in human RCC samples [12]. These results thus confirmed a general reduction of aerobic mitochondrial metabolism in the RCC 786-O xenograft model.

\section{Ketogenic diets reduce tumor growth but also overall survival of tumor bearing mice}

All three KDs (LCT only; LCT/MCT8 - LCTs enriched with 25\% 8-carbon MCTs; LCT/MCT10 - LCTs enriched with 25\% 10-carbon MCTs) tended to slow down tumor growth compared to the control diet, although not significantly (Figure 2A1-2A4, 2B). Surprisingly, the KDs also tend to reduce the overall survival of the tumor bearing mice and this was significantly lower in the mice fed with LCT/MCT10. Mice that received the control diet (CTRL) showed $60 \%$ overall survival at the end of the experiment (65 days), those on the LCT diet showed $50 \%$ survival, whereas mice receiving the LCT/MCT8 and LCT/MCT10 diets showed the worst survival, with only $20 \%$ and $17 \%$ survivors, respectively (Figure $2 \mathrm{C}$ ).

Interestingly, mice with RCC xenografts frequently experienced massive and usually sudden weight loss, which was worse in all the $\mathrm{KD}$ groups compared to the CTRL group (Figure 3A1-3A4). Weight loss greater than $20 \%$ was the only reason for the early termination of treatment and euthanasia. Mice receiving either of the MCT-containing diets experienced pronounced weight loss. In the CTRL group mice maintained a fairly stable body weight until 50-60 days (Figure 3A1). In striking contrast, all tumor bearing mice receiving an LCT diet experienced weight loss after 26-30 days of treatment, and $67 \%$ of them lost more than $20 \%$ of their initial weight (Figure 3A2). In the LCT/MCT8 group, $40 \%$ experienced significant weight loss after 15-20 days (Figure 3A3) and 


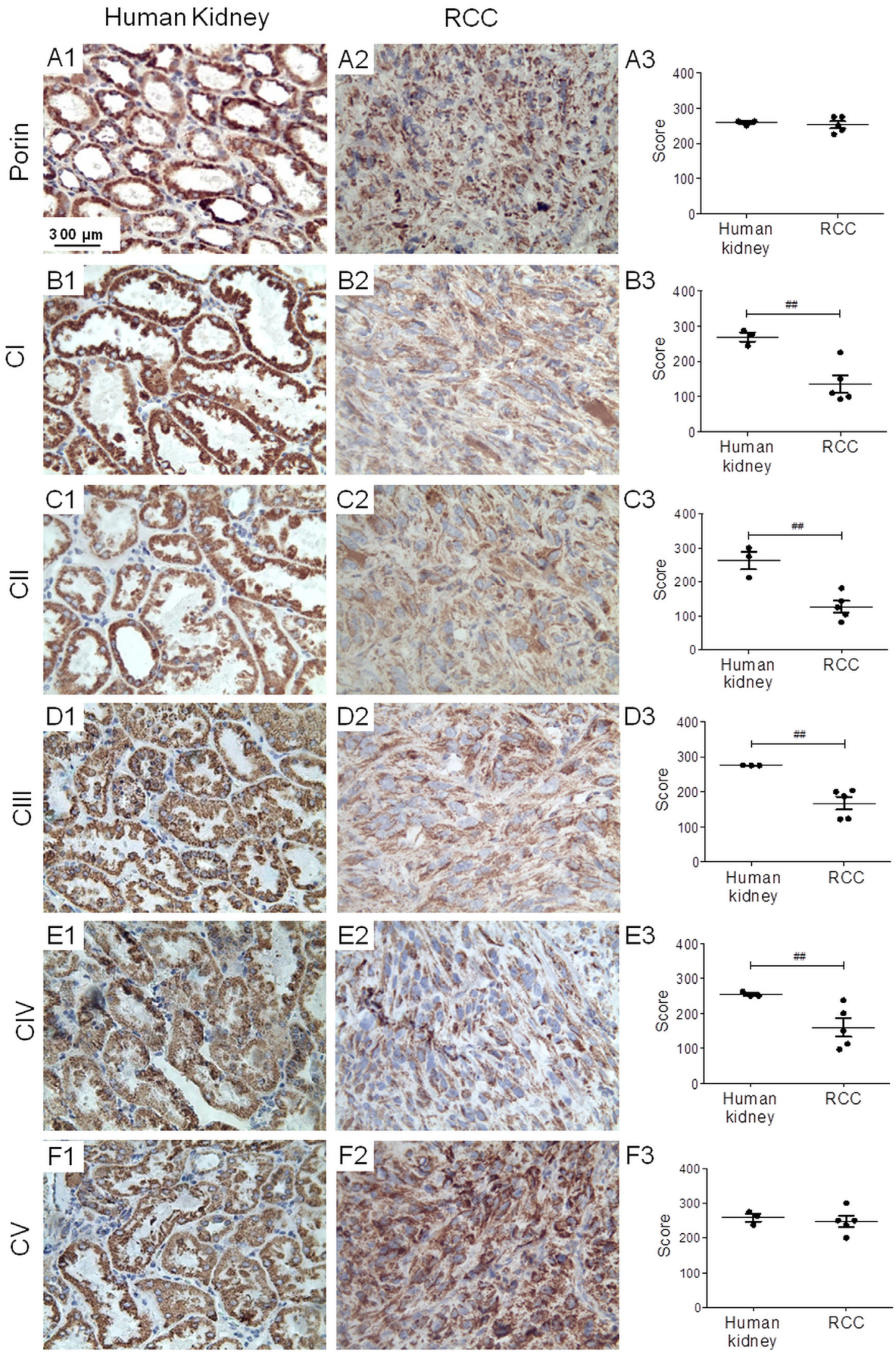

Figure 1: RCC shows reduced levels of OXPHOS complexes I-IV. Immunohistochemical staining of porin and the OXPHOS complexes was performed (A1-F1) on normal human kidney, (A2-F2) and on RCC xenografts. (A3-F3) Graphs indicate score values of staining intensity. Data are given as mean \pm SEM. Statistical analysis was performed by using student's $t$ test (unpaired samples), ${ }^{\# \#} p<0.01$; $n=3$ (human kidney) and $n=5$ (RCC). CI-CV, complexes I-V. 
in the LCT/MCT10 group, about $70 \%$ of the mice began to lose weight as early as 10 days after commencement of the treatment (Figure 3A4). Mice experiencing weight loss seemed a little lethargic (data not shown, subjective observation of the experimenter).

All three KDs provoked in the mice with RCC xenografts a pronounced and significant increase in the concentration of blood ketone bodies during the first week of treatment. The LCT group had a significantly higher blood ketosis until day 50, whereas that of the two LCT/
MCT groups dropped to nearly normal levels after 15 days (Figure 3B). In contrast, average blood glucose levels remained quite stable throughout the 65 days of treatment (Figure 3C).

\section{Ketogenic diets are well tolerated by healthy CD-1 nu/nu mice}

In light of the results obtained with $\mathrm{RCC}$ bearing mice, we tested whether the 8:1 KD per se induced

\section{A1}

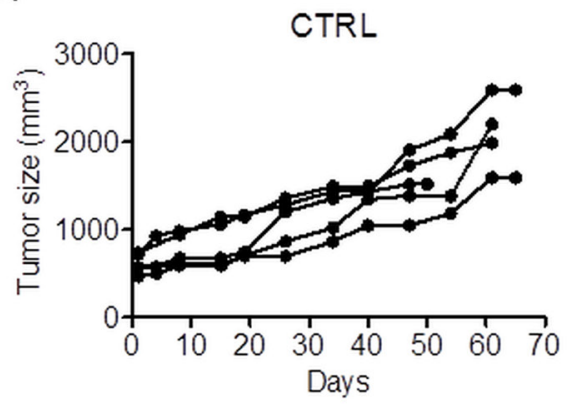

A3

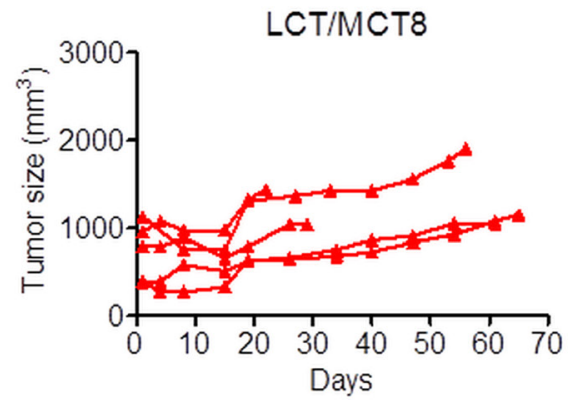

B

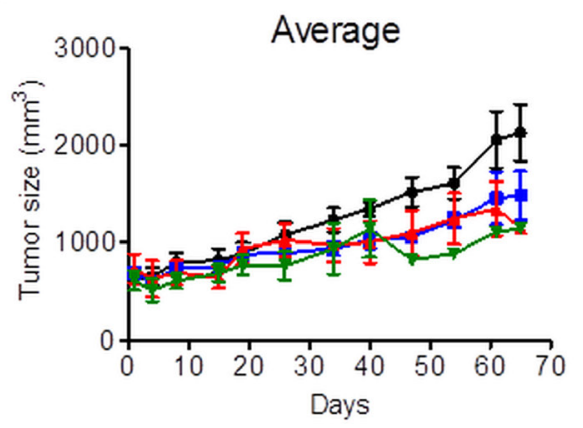

A2

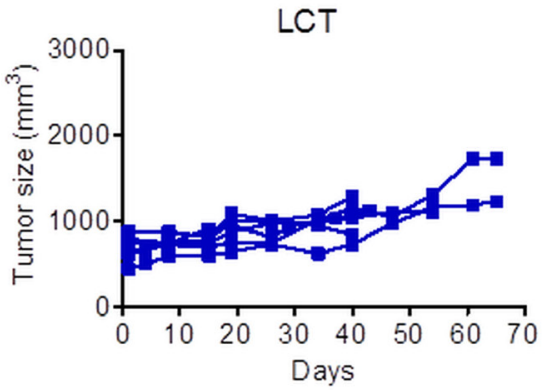

A4

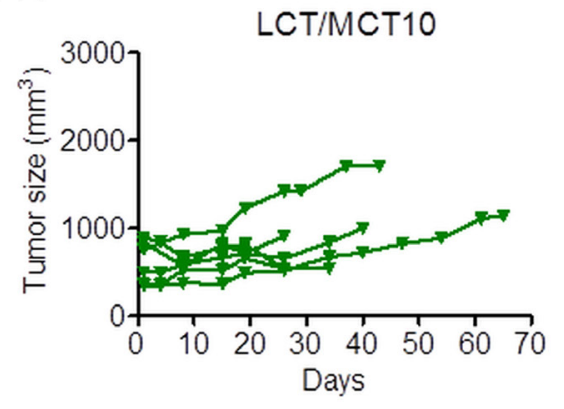

C

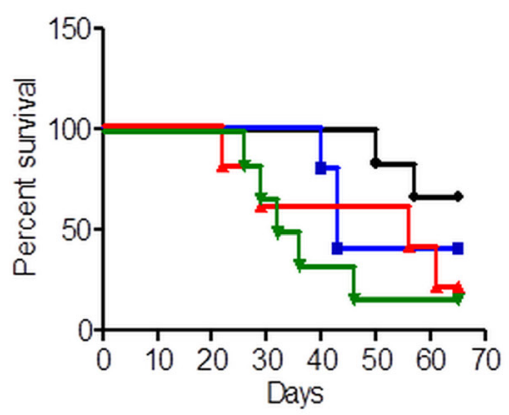

\section{- CTRL घ LCT \\ \ LCT/MCT8 $\nabla$ LCT/MCT10}

Figure 2: KDs generally caused a reduction in tumor growth, but also survival. (A1-A4) Tumor growth in individual mice under different diets. (B) The graph shows the mean of the tumor mass during the treatment time. Data are given as mean $\pm \mathrm{SEM}$. Statistical analysis was performed by using two-way ANOVA (Dunnett's multiple comparison test), $n=5$ for CTRL and LCT/MCT8 groups; $n=6$ for LCT and LCT/MCT10 groups, at the start of the dietary intervention. (C) Kaplan-Meier survival curves for the RCC xenograft recipients treated with the different KDs. The statistical analysis for the survival curves was done with the Log-rank test (Mantel-Cox): CTRL vs. LCT, $p=0.2414$; CTRL vs. LCT/MCT8, $p=0.1205$; CTRL vs. LCT/MCT10, $p=0.0204$. 
altered food intake and weight loss, by feeding healthy mice for 40 days with CTRL, LCT, LCT/MCT8 and LCT/MCT10 diets. The food consumption in the KD groups was in average less, compared to the CTRL group (Supplementary Figure 1A). However, the average calorie intake was similar for the LCT and the CTRL groups and even significantly higher in the LCT/MCT8 and LCT/ MCT10 groups (Supplementary Figure 1B). Importantly,

A1

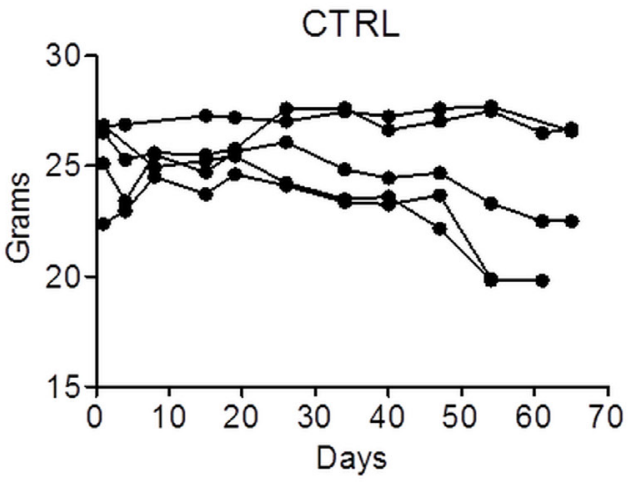

A3

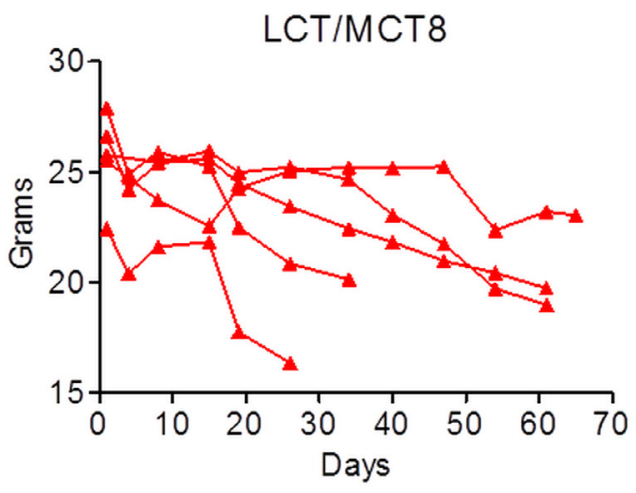

B

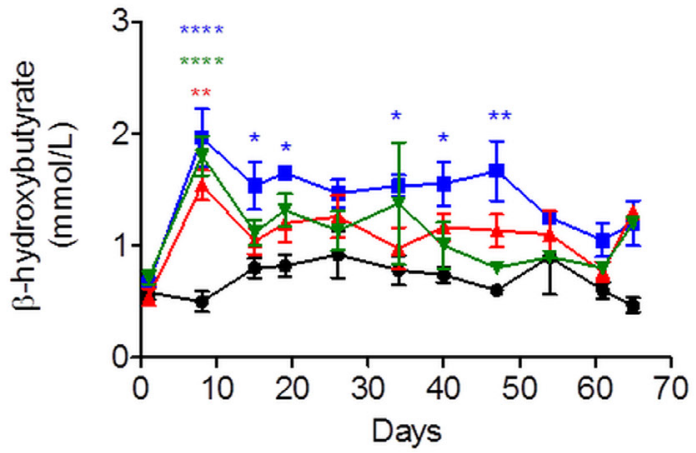

the healthy mice did not experience weight loss in any of the dietary intervention groups; on the contrary they all stably gained weight. Only in the first 3-5 days from the beginning of the dietary intervention, mice in the LCT/MCT8 and LCT/MCT10 groups experienced a mild weight loss (Supplementary Figure 1C). Such a temporary weight loss is a normal consequence in the adaptation from one diet to another. In the first days the food intake in

A2

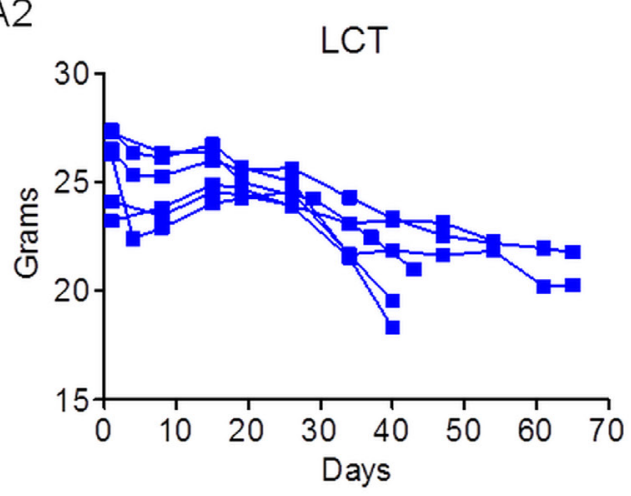

A4

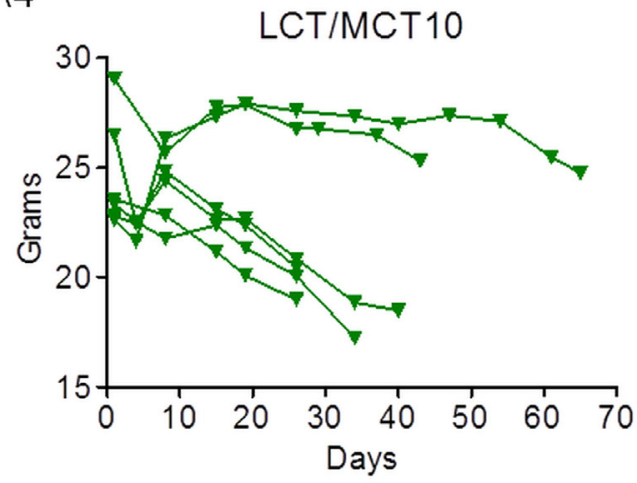

C

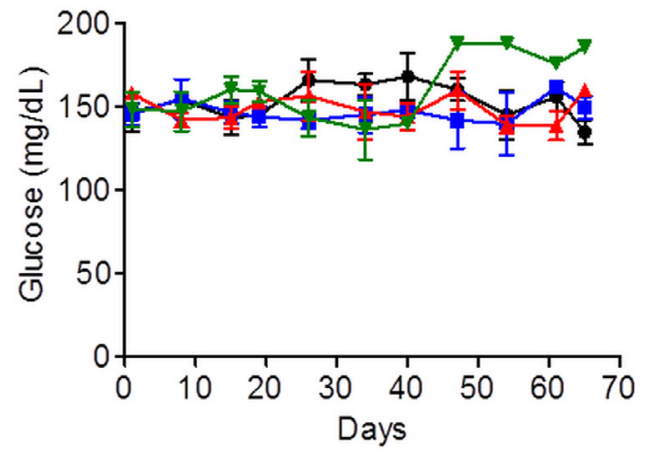

\section{- CTRL — LCT}

\section{^ LCT/MCT8 $\nabla$ LCT/MCT10}

Figure 3: KDs boosted weight loss, increased blood ketone body levels at the beginning of therapy, and did not affect blood glucose levels. (A1-A4) Body weight variations in individual RCC xenograft bearing mice during dietary intervention. (B) Average blood ketone bodies $(\mathrm{mmol} / \mathrm{L})$ and $(\mathbf{C})$ average blood glucose $(\mathrm{mg} / \mathrm{dL})$ levels. Data are given as mean $\pm \mathrm{SEM}$. Statistical analysis was performed by using two-way ANOVA (not repeated measures, Bonferroni post-test), ${ }^{*} p<0.05,{ }^{* *} p<0.01,{ }^{* * *} p<0.001 ; n=5$ for CTRL and LCT/MCT8 groups; $n=6$ for LCT and LCT/MCT10 groups, at the start of the dietary intervention. 
all diet groups was in average 1-1.5 grams/mouse/day and subsequently increased and stabilized to a daily intake per mouse of $3.4 \pm 0.09$ grams in the CTRL group, $1.9 \pm 0.08$ grams in the LCT group, $2.2 \pm 0.15$ grams in the LCT/ MCT8 group and $2.4 \pm 0.15$ grams in the LCT/MCT10 group.

In contrast to the results obtained with the mice bearing the RCC xenografts, the healthy mice under the different KDs presented with a stable and sustained increase of blood ketone levels, compared to the CTRL fed mice (Supplementary Figure 1D), whereas glucose was not significantly affected by the LCT and the LCT/ MCT8 diets, but mildly decreased in the LCT/MCT10 diet, compared to the CTRL group (Supplementary Figure 1E).

\section{KD does not affect common markers of liver dysfunction}

Because patients with RCC often develop paraneoplastic syndrome with non-metastatic hepatic dysfunction $[35,36]$, liver dysfunction or inflammation could be the underlying cause of the weight loss seen in our xenograft model. Therefore, we analyzed biochemical markers of liver function in our experimental mice.

In some cases, the livers of mice bearing RCC in the KD groups exhibited a fatty appearance macroscopically (Figure 4A). However, we found no significant increase in any of the parameters routinely used as indicators of liver dysfunction, i.e., alkaline phosphatase (ALP), alanine aminotransferase (ALT), aspartate aminotransferase (AST), cholinesterase (CHE) and lactate dehydrogenase (LDH) (Figure 4B-4F). Moreover, although AST (Figure 4D), CHE (Figure 4E) and LDH (Figure 4F) were not significantly affected by the presence of the tumor or the type of dietary intervention, the levels of ALP (Figure 4B) and ALT (Figure 4C) were significantly reduced in xenograft-bearing mice compared to control mice without a tumor. Furthermore, the levels of ALP and ALT were not increased in the KD groups compared to the CTRL group; on the contrary, mice receiving the LCT diet had reduced ALP levels (Figure 4B).

To investigate whether the fatty appearance of the liver was due to the presence of fat droplets in the liver, we performed Oil Red $\mathrm{O}$ staining of hepatic sections (Supplementary Figure 2) of the xenograft bearing mice. The images framed in red show the liver parenchyma of mice that exhibited extreme weight loss. Only mouse 1 and mouse 2 in the LCT group showed a higher level of fat droplets, but the amount of red staining did not correlate with a reduction in survival.

\section{RCC is associated with increased mRNA levels of inflammatory cytokines in the liver}

Because non-metastatic paraneoplastic syndrome of the liver is associated with inflammatory cytokines released by the tumor, e.g., interleukin-6 (IL-6) and tumor necrosis factor alpha $(\mathrm{TNF} \alpha)$ [37-40], we examined the mRNA levels of these cytokines in both tumor tissue and the livers of xenograft and control mice. In addition, we measured the mRNA levels of C-reactive protein (CRP) in the liver, as CRP is a hepatic marker of the acute phase of inflammation, and its level depends on IL-6 secretion [41].

The mRNA levels of TNF $\alpha$ and IL-6 were both high in the xenografts of mice under CTRL diet, compared to the original 786-O cells (Figure 5A, 5B). However, the xenografts in all three KD groups exhibited significantly decreased TNF $\alpha$ (but not IL-6) expression (Figure 5C, 5D). Interestingly, TNF $\alpha$ and CRP were both increased in the livers of mice bearing tumors compared to healthy control mice (Figure 6C, 6E). All three KD groups displayed significantly enhanced expression of IL-6 and/or CRP in the liver of the tumor bearing mice (Figure 6A, 6E). Also, a trend for elevated hepatic TNF $\alpha$ expression in the LCT and LCT/MCT8 groups was observed in the mice with tumor. These findings suggest that KD tends to promote inflammation and stress in the livers of RCC-xenograft bearing mice.

To demonstrate that the KDs per se were not causing liver damage, the same cytokines were also measured in the liver of the healthy mice fed with the CTRL diet or the KDs. Notably, the mRNA levels of IL-6, $\mathrm{TNF} \alpha$ and CRP were not increased and the expression of CRP was even significantly decreased in the LCT/MCT10 fed healthy mice, compared to the CTRL fed healthy mice (Figure 6B, 6D, 6F).

\section{DISCUSSION}

KD has been proven to be an effective adjuvant therapy in some types of solid tumors, including neuroblastoma, glioblastoma multiforme, and head and neck cancer [26, 28, 33, 42]. Furthermore, KD helps to protect normal cells from the toxicity of conventional therapies and it sensitizes tumor cells to the therapy, thus lowering the incidence of resistance [18, 19]. Besides affecting metabolism, KD has multiple effects on the regulation of inflammation and cell signaling, through its control of hormones and growth factors. Moreover, KD seems to prevent cachexia in mouse models of cancer $[43,44]$, making the KD an interesting option for the treatment of cancer patients, since advanced stage cancer patients can often experience cancer-induced cachexia [45, 46]. This makes KD a potent therapy for the treatment of many diseases; indeed, it is successfully used in the treatment of drug-resistant epilepsy in children $[47,48]$ and certain metabolic diseases such as pyruvate dehydrogenase deficiency and glucose transporter type 1 deficiency [49-51]. However, the precise mechanism(s) behind its efficacy is still being evaluated.

Our results suggest that RCC tumor bearing mice on a KD might experience reduced tumor growth; however, 
the data are not significant because of the low number of mice $(<3)$ that reached to the termination point of the experiment, due to the severe weight loss. Recently, another study reported that mice with xenografts generated with another RCC cell line (RXF393) also experienced severe weight loss, cachexia and muscle wasting [52], suggesting that the effect is tumor type-specific. Indeed, since the healthy mice fed with the KDs remained healthy throughout the dietary intervention, it is reasonable to conclude that the used KDs are not per se causing these symptoms.

Interestingly, one third of human patients affected by RCC experience a paraneoplastic syndrome. Symptoms can include anemia, polycythemia, hypercalcemia, hypertension, fever, cachexia and weight loss [53, 54]. One of the most common paraneoplastic events is a non-metastatic hepatic dysfunction called Stauffer's syndrome, which affects $10-15 \%$ of patients with RCC $[36,53]$. Stauffer's syndrome is mainly associated with renal cancer and has rarely been reported in other types of tumors, such Hodgkin's lymphoma $[55,56]$ or soft tissue sarcoma $[57,58]$. The hepatic dysfunction usually resolves after surgical removal of the tumor. The onset of liver dysfunction is mainly determined by cytokines released by the tumor, such as IL-6 and TNF $\alpha$ [37-39], and it generally provokes fever, weight loss and an unfavorable prognosis [59]. Interestingly, increased IL-6 and TNF $\alpha$ levels were associated in vivo and in vitro with reduced hepatic ketogenesis $[60,61]$, and this could explain the lower plasma ketone levels in the RCC bearing mice under $\mathrm{KD}$, compared to healthy control mice.

IL-6 seems to have a broad range of effects on body metabolism and cancer. For example, in the liver it decreases gluconeogenesis, has anti-inflammatory effects, and shows anti-steatotic potential, but it also promotes liver carcinogenesis [62]. TNF $\alpha$, together with other cytokines, seems to be an inhibitor of food intake, by regulating leptin release by the adipose tissue [63], or other hormones in the brain such $\alpha$-melanocyte stimulating hormone [64], corticotropin releasing factor [65], and serotonin [66]. All these hormones stimulate anorexia and weight loss [67].

In our mouse model, we found that IL-6 was highly expressed in the tumor tissue and, although its expression in the tumors was not altered by the KDs, IL- 6 mRNA levels were significantly increased in the livers of the tumor bearing mice that received the LCT/MCT8 and LCT/MCT10 diets compared to the CTRL group.

Similarly, TNF $\alpha$ expression was high in the tumor tissue, and it was also generally higher in the livers
A

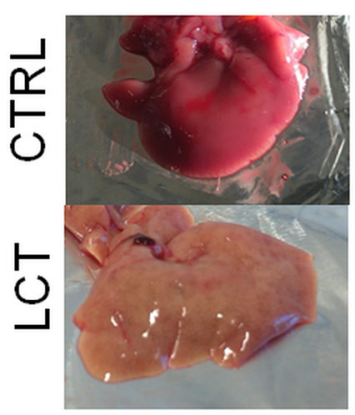

D

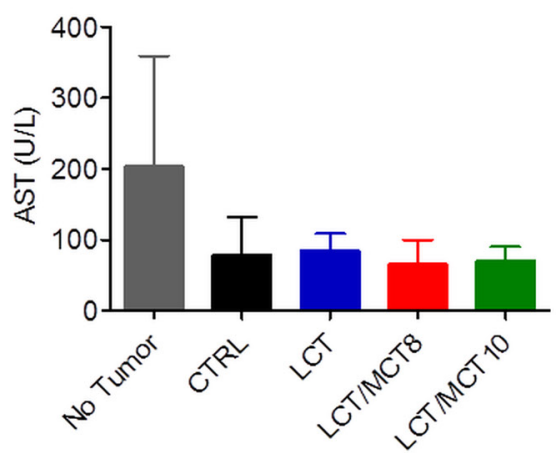

B

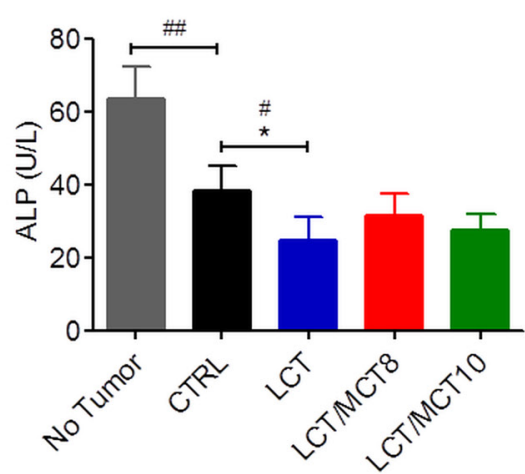

$\mathrm{E}$

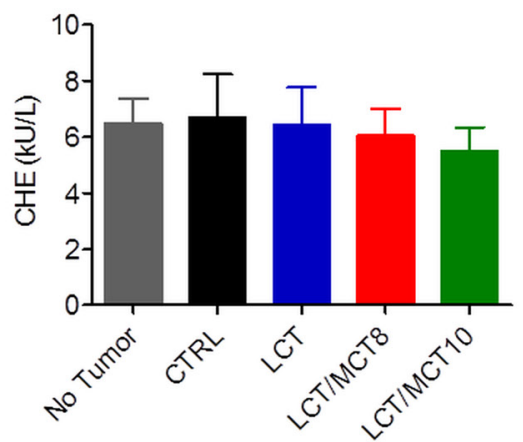

C

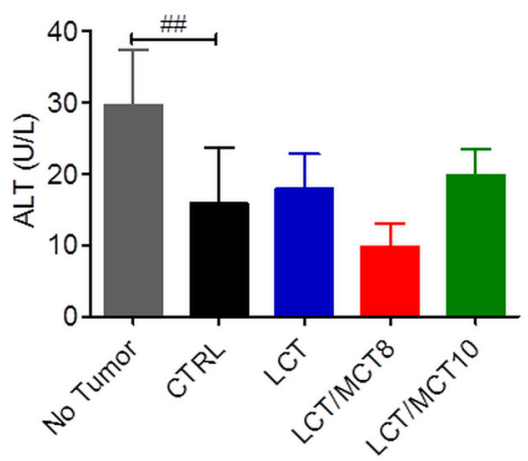

$\mathrm{F}$

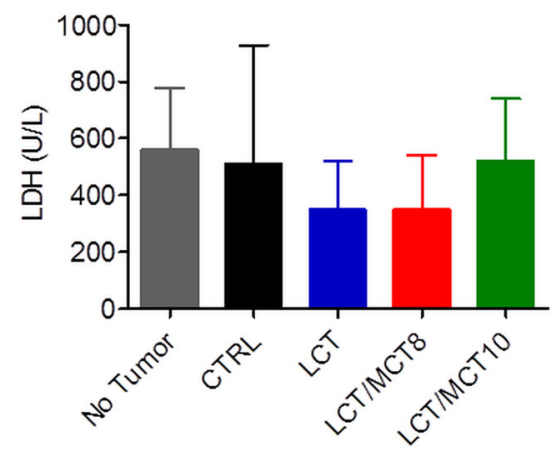

Figure 4: Liver enzymes were not increased in RCC xenograft recipients treated with a KD. (A) Representative images of the liver from a tumor bearing mouse that received a CTRL diet and a tumor bearing mouse that received an LCT diet. Plasma levels of (B) alkaline phosphatase (ALP), (C) alanine aminotransferase (ALT), (D) aspartate aminotransferase (AST), (E) cholinesterase (CHE), (F) lactate dehydrogenase $(\mathrm{LDH})$. Data are given as mean \pm SEM, and statistical analysis was performed by using student's $t$ test (unpaired samples) to compare CTRL vs. a certain KD, ${ }^{*} p<0.05,{ }^{\#} p<0.01$, and one-way ANOVA (Kruskal-Wallis test) was performed to correct to multiple comparison, ${ }^{*} p<0.05 ; n=5$ for CTRL and LCT/MCT8 groups; $n=6$ for LCT and LCT/MCT10 groups. 
of tumor-bearing mice compared to healthy controls. Although the LCT and LCT/MCT8 diets were associated with reduced expression of TNF $\alpha$ in the xenografts, both diets tended to increase its expression in the liver of the mice with xenografts. However, when the KDs were administered to healthy mice, the expression of IL-6 and $\mathrm{TNF} \alpha$ remained unaffected.

CRP is considered a negative marker for overall survival of cancer patients $[68,69]$. Indeed, its expression is responsible for anemia in RCC patients. Importantly, CRP plasma levels rise in response to inflammation. It is an acute-phase hepatic protein, and the levels are increased by IL-6 secretion from macrophages and T cells. The final effect of CRP elevation is activation of the complement system [41].

In our RCC model, the livers of engrafted mice exhibited a significant increase in CRP mRNA levels compared to tumor-free mice. These levels were further increased in the KD-treated mice, indicating that the KDs potentiated this effect. On the contrary, the KDs did not increase the expression of CRP in the liver of healthy mice, and mice fed with LCT/MCT10 even showed a significant decrease of its expression, compared to the CTRL fed animals. This observation confirms that the KDs alone are not causing liver inflammation, and it confirms previous studies showing anti-inflammatory effects of $\mathrm{KD}[25,70,71]$, which might be mediated by $\beta$-hydroxybutyrate action [72].

Surprisingly, there was not a consistent increase in fat droplets in the livers of the xenograft recipients, nor were the plasma levels of biochemical markers of liver dysfunction increased. In fact, two of such markers (ALP and ALT) were decreased, granted a decrease in ALP can also be a sign of malnutrition, severe anemia
A

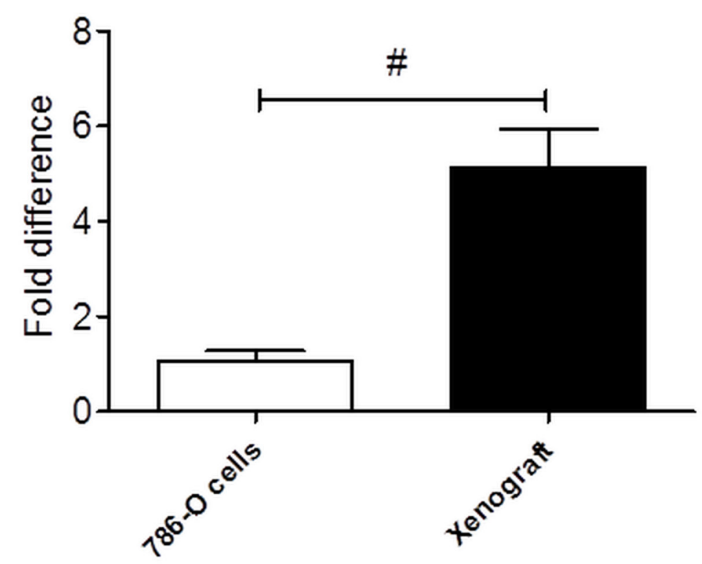

C

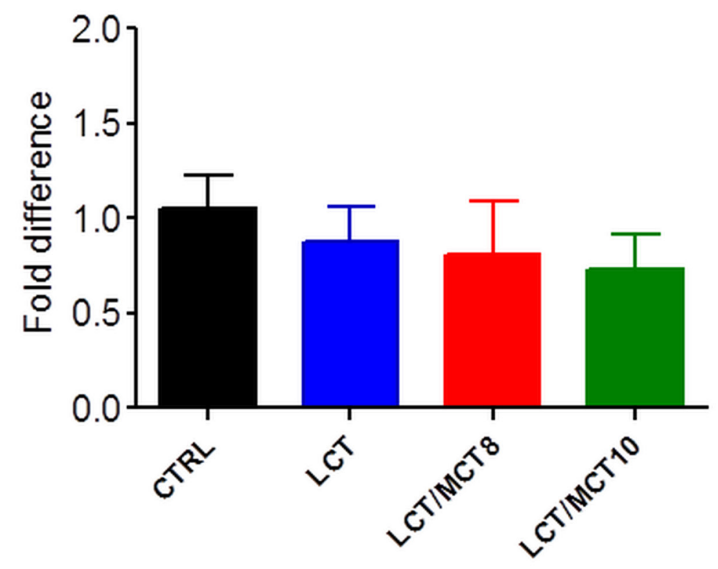

B

\section{TNFa}
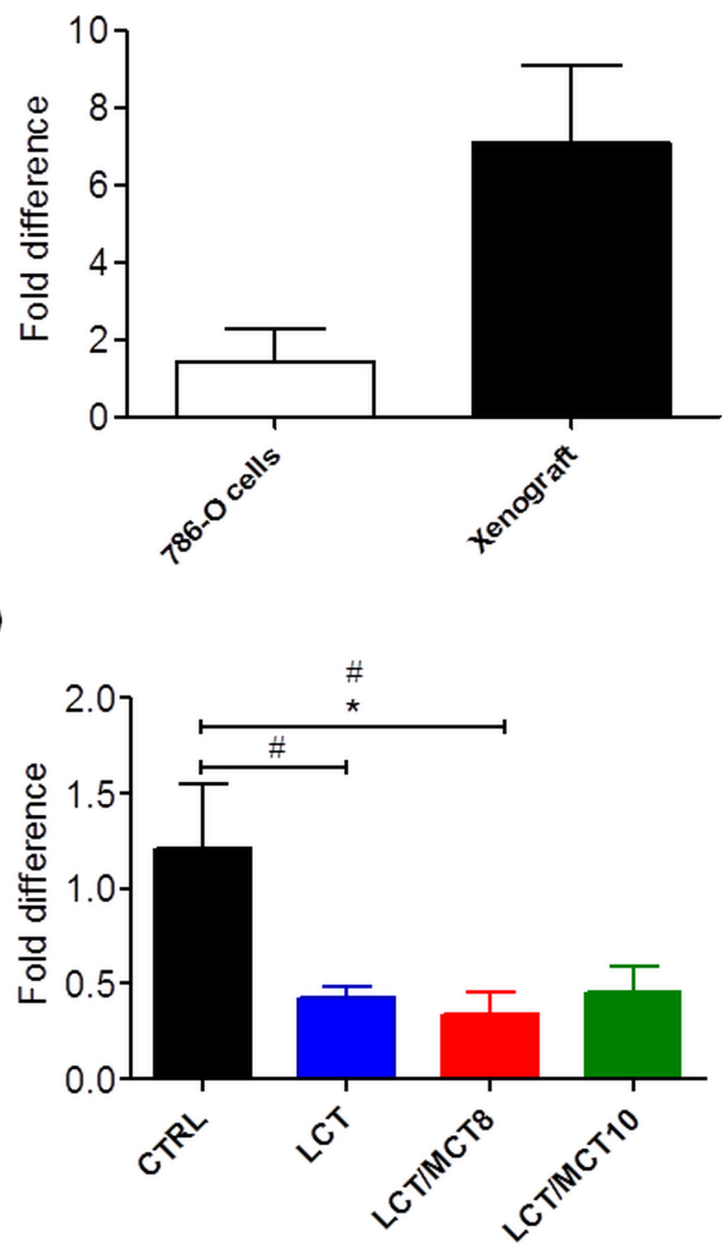

Figure 5: RCC xenografts expressed IL-6 and TNF $\alpha$, but KDs did not increase their expression levels. mRNA expression of (A, C) IL-6 and (B, D) TNF $\alpha$ in RCC xenografts. The xenografts in A and B are from mice fed with CTRL diet. Data are given as mean \pm SEM. Statistical analysis was performed by using student's $t$ test (unpaired samples) to compare CTRL vs. a certain KD, ${ }^{\#} p<0.05$ and one-way ANOVA (Kruskal-Wallis test) was performed to correct to multiple comparison, ${ }^{*} p<0.05 ; n=3$ independent experiments for the 786-O cells; $n=5$ for CTRL and LCT/MCT8 groups; $n=6$ for LCT and LCT/MCT10 groups. 
RCC xenografts

A

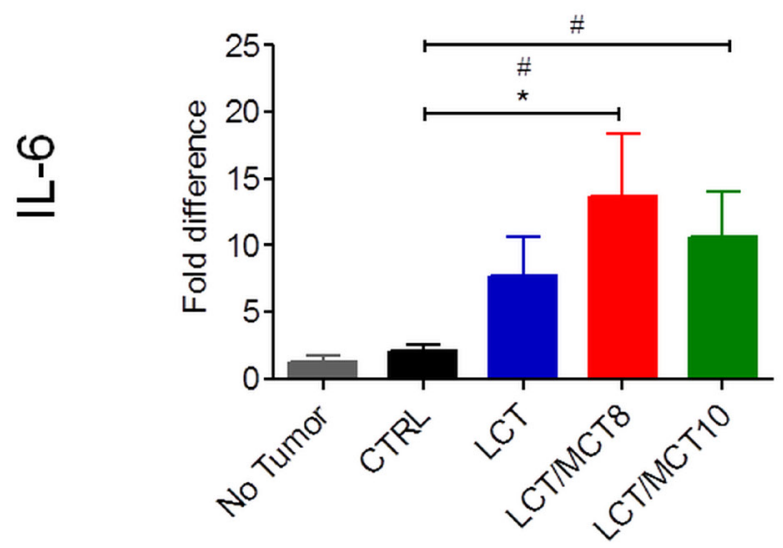

C

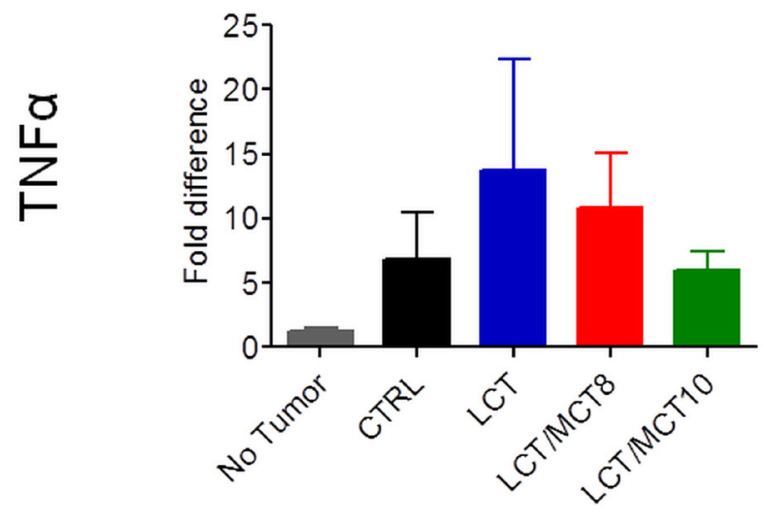

$E$

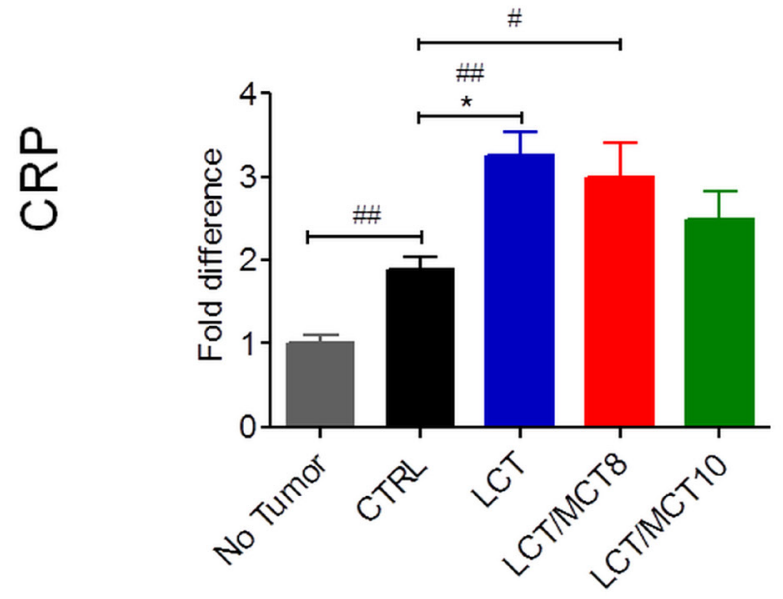

B

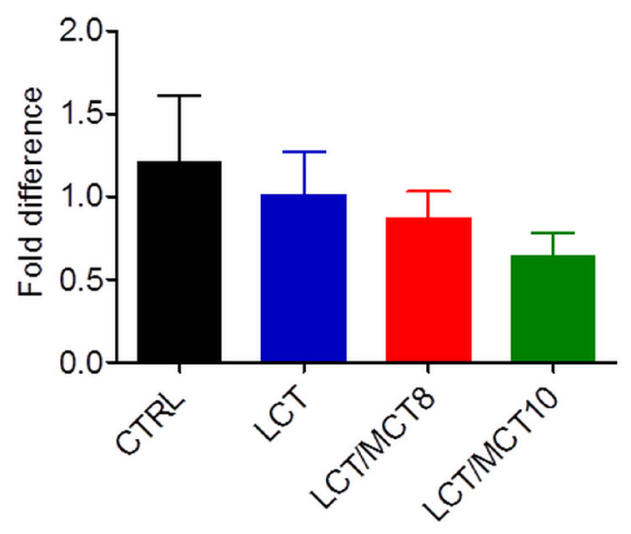

$\mathrm{D}$

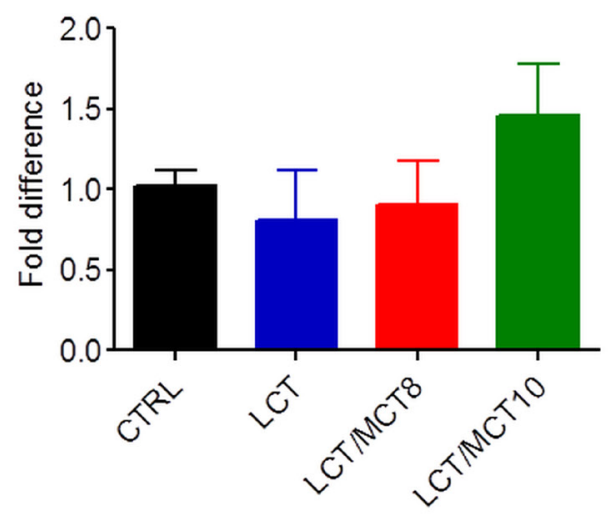

$\mathrm{F}$

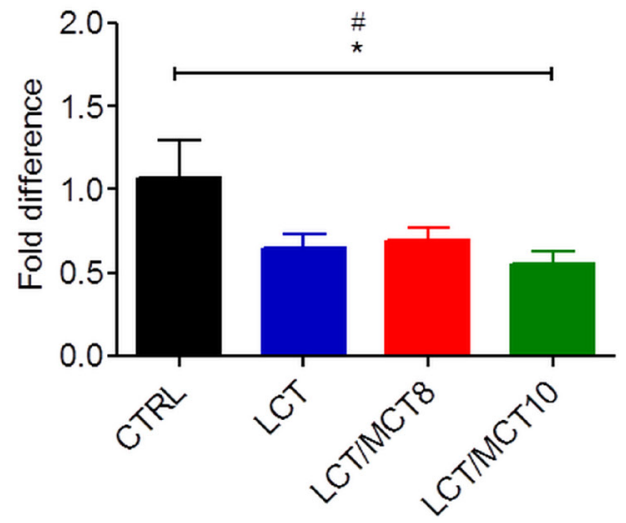

Figure 6: KDs tended to increase inflammatory cytokines in the livers of RCC xenograft recipients, but not in the livers of healthy mice. mRNA levels of (A, B) IL-6, (C, D) TNF $\alpha$ and (E, F) CRP in liver tissue from (A, C, E) RCC bearing mice fed with CTRL or KDs compared to healthy mice fed with CTRL diet, and (B, D, F) from healthy mice fed with CTRL or KDs. Data are given as mean \pm SEM. Statistical analysis was performed by using the student's $t$ test (unpaired samples) to compare CTRL vs. a certain KD, ${ }^{*} p<0.05,{ }^{*} p<0.01$ and one-way ANOVA (Kruskal-Wallis test) was performed to correct to multiple comparison, ${ }^{*} p<0.05$; (A, C, E) $n=4$ for the no tumor group; $n=5$ for CTRL and LCT/MCT8 groups; $n=6$ for LCT and LCT/MCT10 groups; (B, D, F) $n=5$ for CTRL and LCT groups; $n=6$ for LCT/MCT8 and LCT/MCT10 groups. 
and deficiency in magnesium and some vitamins [73]. However, normal liver function tests do not always mean the liver is normal. Patients with cirrhosis, liver fibrosis, or significant hepatic necroinflammation can sometimes present normal liver function tests. Only serum albumin, bilirubin and prothrombin time can provide more useful information on liver status [74, 75], but these tests require additional amounts of blood. However, this was not available due to the small volumes collectable from a single mouse. Thus, we could perform only the standard liver function tests.

Interestingly, a study performed on Eker rat models of tuberous sclerosis showed that long-term (8 months) administration of KD promoted renal tumor growth. Eker mice are characterized by mutations that provoke development of mostly non-neoplastic lesions in many organs [76]. This could have sensitized the kidney to cancer development, but still it suggests a higher susceptibility of the kidney to long-term administration of KD compared to other organs. Taken together, these findings suggest that KD per se does not show signs of toxicity, but that it might be contraindicated for the treatment of RCC, when associated with signs of Stauffer's syndrome. We can not exclude that using a lower fat:carbohydrate ratio than 8:1, might mitigate the effects on the liver and weight loss, this remains however to be tested.

Our study suggests that the feasibility of $\mathrm{KD}$ as an adjuvant cancer therapy strongly depends on the type of cancer and even its genetic alterations. For example, a recent study reported that $\mathrm{KD}$ increased tumor cell proliferation in BRAF positive melanoma but not in BRAF negative melanoma cells [77], confirming that KD has different effects depending on the type and genetics of a tumor. Anyway, one has also to be careful in translating results from animal models into the human practice, as in a human trial involving patients with different types of advanced cancer, a patient presenting with a BRAF positive melanoma was the one which benefited the most [78]. Of course it is impossible to draw conclusions from a single case, and in large scale studies the results could be different.

Thus, it is important to test the practicability of KD in specific tumor types in pre-clinical studies first, and then carefully translate them to human clinical trials.

\section{MATERIALS AND METHODS}

\section{Cell culture}

The most common and aggressive type of RCC exhibits loss of von Hippel-Lindau (VHL) factor and constitutive expression of hypoxic inducible factor (HIF); therefore, we chose 786-O (CRL-1932, ATCC, Germany) cells to establish RCC xenografts. Indeed, 786-O cells are characterized by a truncated form of HIF-1 $\alpha$ and absence of VHL. In RCC, when an HIF-1 $\alpha$ mutation is present, VEGF is controlled by constitutive expression of HIF-2 $\alpha$ [79]. Cells were cultivated in high glucose RPMI-1640 medium (Sigma-Aldrich, Austria) supplemented with heat-inactivated fetal bovine serum (Gibco, Austria) and 100x penicillin/streptomycin amphotericin B solution (Lonza, Germany) diluted 1:100.

\section{Animal experiments}

All in vivo experiments were performed in accordance with protocols approved for this study by the Salzburg Animal Care and Use Committee (No. 20901TVG/87/7-2014). Animals were maintained under specific pathogen-free conditions and care conformed to the Austrian Act on Animal Experimentation. All experiments were performed on female CD-1 nu/nu mice (Charles River, Germany), the animals were group-housed and had unlimited access to food. Feeding of the healthy mice with the experimental diets started on 7 weeks old mice.

Food consumption was calculated by subtracting the grams of remaining food from the grams of added food, and then dividing by the number of mice present in the cage and the number of days; measurements were performed every 3-4 days.

Xenografts were established in 5- to 6-week-old mice by injection of $200 \mu \mathrm{l}$ of a $1: 1$ suspension of $10^{7}$ cells in serum-free medium and matrigel into the right flank (BD Biosciences, Austria).

When tumor size reached 600-700 $\mathrm{mm}^{3}$, mice were randomized into different ad libitum dietary intervention groups ( $n=5-6)$ and group-housed. Xenograft recipients were monitored twice a week for body weight using a digital scale, and tumor volume by using a caliper and calculating the volume according to the formula (width $\times$ height $\times$ length) $/ 2$. Blood glucose and ketone body ( $\beta$-hydroxybutyrate) levels were monitored once a week using a specific enzyme-based kit (Precision Xceed, Abbott Laboratories, Austria). Measurements were performed after a two-hour fasting period.

For the xenografts, mice were euthanized 65 days after injection of tumor cells or when termination criteria were reached, such weight loss above $20 \%$ of the net body weight; none of the mice was scarified due to the tumor size, since none of the xenografts reached the termination size of $10 \%$ of the net mouse weight. One $5-\mathrm{mm}$ thick slice from the central part of the tumor was formalin-fixed and paraffin-embedded for histological analysis, and the remaining cancer tissue was snap frozen in liquid nitrogen. Livers were also collected and snap frozen in liquid nitrogen. Finally, prior to being sacrificed, mice were injected with $10 \mu \mathrm{l} / \mathrm{g}$ of anesthetic mix (ketamine $20.5 \mathrm{mg} / \mathrm{ml}$, xylazine $5.4 \mathrm{mg} / \mathrm{ml}$, acepromazine $270 \mu \mathrm{g} / \mathrm{ml}$ in saline solution), and after checking for absence of reflexes from the paw, heart puncture was performed and blood was collected into tubes (BD Microtainer ${ }^{\circledR}$ PST $^{\mathrm{TM}} \mathrm{LH}$ 
tubes) (BD Biosciences, Austria). As suggested in the manufacture's protocol, tubes were inverted 10 times and centrifuged at $10000 \mathrm{~g}$ for 90 seconds to separate plasma; plasma was then collected and snap frozen in liquid nitrogen.

The experiment on healthy animals was terminated after 40 days of treatment and the same protocol for the euthanasia and the sample collections used for the xenograft bearing mice was applied. All frozen samples were stored at $-80^{\circ} \mathrm{C}$ until analysis.

\section{Dietary intervention}

Mice were randomized into four dietary groups fed ad libitum: control diet (CTRL); long-chain fatty acid KD (LCT); 25\% 8-carbon medium-chain fatty acids and $49.6 \%$ LCT KD (LCT/MCT8); and 25\% 10-carbon mediumchain fatty acids and 49.6\% LCT KD (LCT/MCT10) (Sniff Spezialdiäten GmbH, Germany). Moreover, diets were fortified with vitamins and minerals (Table 1).

\section{Murine plasma screening for liver dysfunction}

The plasma collected from the mice after sacrification was analyzed for common liver function markers (alkaline phosphatase, alanine aminotransferase, aspartate aminotransferase, cholinesterase and lactate dehydrogenase) by standard laboratory methods on a COBAS 8000 instrument (Roche Diagnostics, Germany) [80].

\section{(Immuno-)histochemical staining}

Immunohistological stainings were performed on $4-\mu \mathrm{m}$ deparaffinized sections. Human control kidney tissue was obtained from the Department of Pathology (Paracelsus Medical University, Salzburg). For the immunohistochemistry of porin and OXPHOS complexes I-V the following antibodies were used: mouse monoclonal anti-complex I subunit NDUFS4 (1:1000; Abcam, UK), mouse monoclonal anticomplex II subunit SDHA (1:3000; Abcam, UK), mouse monoclonal anti-complex III subunit core 2 (1:1000; Abcam, UK), mouse monoclonal anti-complex IV subunit I (1:1000; Abcam, UK), mouse monoclonal anti-complex V subunit- $\alpha$ (1:2000; Abcam, UK) and mouse monoclonal anti-voltage-dependent anion channel (VDAC1)/porin (1:2000; Abcam, UK). All antibodies were diluted in Dako antibody diluent with background reducing components (Dako, Denmark). The immunohistological stainings were performed as previously described [81].

A scoring system was used to quantify differences in expression levels between tumor and control human kidney tissue, as follows: the staining intensity ( 0 : no staining; 1: weak staining; 2: moderate staining; 3: strong staining) was multiplied by the mean percentage of immunopositive cells. The score for each section was calculated as the mean of 4 high-power fields.

Oil Red O staining was performed on $6-\mu \mathrm{m}$ thick cryosections. A stock solution was prepared by dissolving $3.75 \mathrm{~g}$ Oil Red O powder (Sigma-Aldrich, Austria) in $1000 \mathrm{ml}$ of 2-propanol (Merck-Millipore, Germany). The working solution was prepared by adding $40 \mathrm{ml}$ of distilled water into $60 \mathrm{ml}$ of stock solution, and filtering through a Whatman ${ }^{\circledR}$ filter (Sigma-Aldrich, Austria). Cryosections were taken from the $-80^{\circ} \mathrm{C}$ storage, air dried for $10 \mathrm{~min}$ and then fixed for $20 \mathrm{~min}$ in $4 \%$ formaldehyde solution (Merck-Millipore, Germany). After fixation, the sections were washed twice for $5 \mathrm{~min}$ with distilled water and air dried for another $10 \mathrm{~min}$. Slides were then dipped into $50 \%$ ethanol (Merck-Millipore, Germany), followed by a 20 min incubation in Oil Red $\mathrm{O}$ working solution and more dips into 50\% ethanol. Afterwards, the slides were rinsed in distilled water and incubated for $3 \mathrm{~min}$ in Hematoxylin solution (Merck-Millipore, Germany). Finally, the slides were washed for $5 \mathrm{~min}$ under running tap water and mounted using Aquatex ${ }^{\circledR}$ (Merck-Millipore, Germany).

\section{Quantitative real-time PCR}

RNA of tumor and liver tissue was isolated using TRI-Reagent (Molecular Research Center, USA) following the manufacturer's protocol. Genomic DNA contamination was eliminated with the Turbo DNA-free Kit (Thermo Scientific, Austria) according to the manufacturer's instructions. Maxima Reverse Transcriptase (Thermo Scientific, Austria) and random hexamer primers were used for cDNA synthesis as recommended in the manufacturer's protocol. For gene quantification, iQ SYBR green supermix (Bio-Rad, USA) was used. Primers were synthesized by Microsynth (Switzerland). Target sites of the forward and reverse primers were separated by at least one intron (Human: IL-6: fwd 5'- AGATGT AGCCGCCCCACACAG -3', rev 5'- CCAGTGCCTCTTT GCTGCTTTCA -3'; TNF $\alpha$ : fwd 5'- CCTGCTGCACTTT GGAGTGA -3', rev 5'- CTTGTCACTCGGGGTTCGAG -3'; Ribosomal protein L 27 (RPL27): fwd 5'-GCTGGAA TTGACCGCTACC-3', rev 5'-TCTCTGAAGACATCC TTATTGACG-3'; murine: IL-6: fwd 5'- CCGGAGAGGAG ACTTCACAGAGG -3', rev 5'- TCTGCAAGTGCATC ATCGTTGT -3'; TNF $\alpha$ : fwd 5'- GGTCCCCAAAGGGAT GAGAA -3', rev 5'- CTCAGCCACTCCAGCTGCTC -3'; CRP: fwd 5'- TCCCAGCAGCATCCATAGCCA -3', rev 5'- TGGCTTCTTTGACTCTGCTTCCA -3'; RPL4: fwd 5'- GTATGGCACTTGGCGGAAGG -3', rev 5'- TG CTCGGAGGGCTCTTTGG $\left.-3^{\prime}\right)$. The amplification reaction was performed for 45 cycles $\left(97^{\circ} \mathrm{C}\right.$ for 15 seconds, $63^{\circ} \mathrm{C}$ human or $64^{\circ} \mathrm{C}$ mouse for 30 seconds and $72^{\circ} \mathrm{C}$ for 10 seconds) in duplicates. The relative expression of the genes was determined by the difference between the threshold cycle $(\mathrm{Ct})$ of the gene of interest and the $\mathrm{Ct}$ of the housekeeping gene RPL27 for human and RPL4 for murine transcripts. 
Table 1: Composition and energy supply of the different diets

\begin{tabular}{|c|c|c|c|c|}
\hline & CTRL & LCT & LCT/MCT8 & LCT/MCT10 \\
\hline Crude Protein \% & 16.1 & 8.1 & 8.1 & 8.1 \\
\hline LCT $\%^{a}$ & 7.1 & 74.6 & 49.6 & 49.6 \\
\hline MCT8 \% ${ }^{\mathrm{b}}$ & 0 & 0 & 25 & 0 \\
\hline MCT10 $\%^{\mathrm{b}}$ & 0 & 0 & 0 & 25 \\
\hline Sugar $\%$ & 6 & 1 & 1 & 1 \\
\hline Starch \% & 51.2 & 0 & 0 & 0 \\
\hline Crude fiber $\%$ & 10 & 9.9 & 9.9 & 9.9 \\
\hline Crude ash \% & 4.5 & 4.4 & 4.4 & 4.4 \\
\hline \multirow[t]{2}{*}{ Energy Kcal } & 3609 & 7098 & 7098 & 7098 \\
\hline & per $\mathrm{Kg}$ & per $\mathrm{Kg}$ & per $\mathrm{Kg}$ & per $\mathrm{Kg}$ \\
\hline Vitamin A (IU/IE) & 15 & 15 & 15 & 15 \\
\hline Vitamin $\mathrm{D}_{3}(\mathrm{IU} / \mathrm{IE})$ & 1.5 & 1.5 & 1.5 & 1.5 \\
\hline Vitamin E (mg) & 150 & 150 & 150 & 150 \\
\hline Vitamin $\mathrm{K}_{3}(\mathrm{mg})$ & 20 & 20 & 20 & 20 \\
\hline Vitamin C (mg) & 30 & 30 & 30 & 30 \\
\hline Copper (mg) & 11 & 11 & 11 & 11 \\
\hline
\end{tabular}

CTRL, control; LCT, long-chain triglyceride; MCT8, 8-carbon medium-chain triglyceride; MCT10, 10-carbon medium-chain triglyceride.

${ }^{a}$ LCT composition: butter fat $11.7 \%$ and pork lard $88.3 \%$

${ }^{\mathrm{b}} \mathrm{MCT} 10$ and MCT8 composition: pure oil

\section{Statistical analysis}

Statistical analyses were performed using Prism 6 (GraphPad Software, USA). Results are given as mean \pm SEM. Student's $t$ test (unpaired samples) was applied to compare two groups, one-way ANOVA (KruskalWallis test) or two-way ANOVA (not repeated measures, Bonferroni post-test), to compare more than one group and correct for multiple comparison.

\section{Abbreviations}

ALP, alkaline phosphatase; ALT, alanine transferase; AST, aspartate aminotransferase; CHE, cholinesterase; CRP, C-reactive protein; CTRL, control; HIF, hypoxia inducible factor; IL-6, interleukin-6; KD, ketogenic diet; LCT, long-chain triglyceride; LDH, lactate dehydrogenase; MCT8, 8-carbon medium-chain triglyceride; MCT10, 10-carbon medium-chain triglyceride; RCC, renal cell carcinoma; RPL, ribosomal protein $\mathrm{L}$; $\mathrm{TNF} \alpha$, tumor necrosis factor alpha; VHL, von Hippel-Lindau.

\section{Authors' contributions}

SV participated in designing the study, performed, oversaw and analyzed experiments and drafted the manuscript. SAG, RV, FL contributed to the in vivo experiments. AK contributed to the mRNA analysis. RGF, BK designed and supervised the study and wrote the ethical proposal. TKF analyzed the plasma samples. TR, MOD, ASK, BL designed the diets and provided materials. WS contributed with expertise in mitochondrial energy metabolism and critical discussion. All authors read, edited and approved the final manuscript.

\section{ACKNOWLEDGMENTS}

The authors would like to thank Julia Stockinger and David Schwarzenbacher for their excellent technical support and Johannes A Mayr for comments and suggestions.

\section{CONFLICTS OF INTEREST}

The authors state no conflicts of interest.

\section{FUNDING}

This work was supported by the Marie Curie Initial Training Network MEET (317433) and the Austrian Research Promotion Agency (822782/THERAPEP).

\section{REFERENCES}

1. Ljungberg B, Campbell SC, Choi HY, Jacqmin D, Lee JE, Weikert S, Kiemeney LA. The epidemiology of renal cell carcinoma. Eur Urol. 2011; 60:615-621. 
2. Low G, Huang G, Fu W, Moloo Z, Girgis S. Review of renal cell carcinoma and its common subtypes in radiology. World J Radiol. 2016; 8:484-500.

3. Shinder B, Farber NJ, Mayer T, Singer EA. Treatment of Multifocal Renal Cell Carcinoma in a Solitary Kidney With Nivolumab. Clin Genitourin Cancer. 2016; 15:e165-e167.

4. Kinnaird A, Dromparis P, Saleme B, Gurtu V, Watson K, Paulin R, Zervopoulos S, Stenson T, Sutendra G, Pink DB, Carmine-Simmen K, Moore R, Lewis JD, et al. Metabolic Modulation of Clear-cell Renal Cell Carcinoma with Dichloroacetate, an Inhibitor of Pyruvate Dehydrogenase Kinase. Eur Urol. 2016; 69:734-744.

5. Gupta K, Miller JD, Li JZ, Russell MW, Charbonneau C. Epidemiologic and socioeconomic burden of metastatic renal cell carcinoma (mRCC): a literature review. Cancer Treat Rev. 2008; 34:193-205.

6. Morscher RJ, Aminzadeh-Gohari S, Hauser-Kronberger C, Feichtinger RG, Sperl W, Kofler B. Combination of metronomic cyclophosphamide and dietary intervention inhibits neuroblastoma growth in a CD1-nu mouse model. Oncotarget. 2016; 7:17060-17073. https://doi.org/10.18632/ oncotarget.7929.

7. Aminzadeh S, Vidali S, Sperl W, Kofler B, Feichtinger RG. Energy metabolism in neuroblastoma and Wilms tumor. Transl Pediatr. 2015; 4:20-32.

8. Hanahan D, Weinberg RA. Hallmarks of cancer: the next generation. Cell. 2011; 144:646-674.

9. Feichtinger RG, Zimmermann F, Mayr JA, Neureiter D, Hauser-Kronberger C, Schilling FH, Jones N, Sperl W, Kofler B. Low aerobic mitochondrial energy metabolism in poorly- or undifferentiated neuroblastoma. BMC Cancer. 2010; 10:149.

10. Warburg O. Über den Stoffwechsel der Carcinomzelle. Naturwissenschaften. 1924; 12:1131-1137.

11. Tran Q, Lee H, Park J, Kim SH, Park J. Targeting Cancer Metabolism - Revisiting the Warburg Effects. Toxicol Res. 2016; 32:177-193.

12. Meierhofer D, Mayr JA, Foetschl U, Berger A, Fink K, Schmeller N, Hacker GW, Hauser-Kronberger C, Kofler B, Sperl W. Decrease of mitochondrial DNA content and energy metabolism in renal cell carcinoma. Carcinogenesis. 2004; 25:1005-1010.

13. Elias RJ. Chemically-mediated inhibition of hamster buccal pouch epithelial-DNA synthesis in vitro. Northwest Dent Res. 1990; 2:22-24.

14. Feichtinger RG, Zimmermann FA, Mayr JA, Neureiter D, Ratschek M, Jones N, Sperl W, Kofler B. Alterations of respiratory chain complexes in sporadic pheochromocytoma. Front Biosci (Elite Ed). 2011; 3:194-200.

15. Feichtinger RG, Neureiter D, Royer-Pokora B, Mayr JA, Zimmermann FA, Jones N, Koegler C, Ratschek M, Sperl W, Kofler B. Heterogeneity of mitochondrial energy metabolism in classical triphasic Wilms' tumor. Front Biosci (Elite Ed). 2011; 3:187-193.
16. Feichtinger RG, Weis S, Mayr JA, Zimmermann FA, Bogner B, Sperl W, Kofler B. Alterations of oxidative phosphorylation in meningiomas and peripheral nerve sheath tumors. Neuro Oncol. 2016; 18:184-194.

17. Feichtinger RG, Weis S, Mayr JA, Zimmermann F, Geilberger R, Sperl W, Kofler B. Alterations of oxidative phosphorylation complexes in astrocytomas. Glia. 2014; 62:514-525.

18. Mayr JA, Meierhofer D, Zimmermann F, Feichtinger R, Kogler C, Ratschek M, Schmeller N, Sperl W, Kofler B. Loss of complex I due to mitochondrial DNA mutations in renal oncocytoma. Clin Cancer Res. 2008; 14:2270-2275.

19. Calabrese C, Iommarini L, Kurelac I, Calvaruso MA, Capristo M, Lollini PL, Nanni P, Bergamini C, Nicoletti G, Giovanni CD, Ghelli A, Giorgio V, Caratozzolo MF, et al. Respiratory complex I is essential to induce a Warburg profile in mitochondria-defective tumor cells. Cancer Metab. 2013; 1:11.

20. Yusnita Y, Norsiah MD, Rahman AJ. Mutations in mitochondrial NADH dehydrogenase subunit 1 (mtND1) gene in colorectal carcinoma. Malays J Pathol. 2010; 32:103-110.

21. Meierhofer D, Mayr JA, Fink K, Schmeller N, Kofler B, Sperl W. Mitochondrial DNA mutations in renal cell carcinomas revealed no general impact on energy metabolism. Br J Cancer. 2006; 94:268-274.

22. Godinot C, de Laplanche E, Hervouet E, Simonnet H. Actuality of Warburg's views in our understanding of renal cancer metabolism. J Bioenerg Biomembr. 2007; 39:235-241.

23. Lussier DM, Woolf EC, Johnson JL, Brooks KS, Blattman JN, Scheck AC. Enhanced immunity in a mouse model of malignant glioma is mediated by a therapeutic ketogenic diet. BMC Cancer. 2016; 16:310.

24. Vidali S, Aminzadeh S, Lambert B, Rutherford T, Sperl W, Kofler B, Feichtinger RG. Mitochondria: The ketogenic diet--A metabolism-based therapy. Int J Biochem Cell Biol. 2015; 63:55-59.

25. Seyfried TN, Flores R, Poff AM, D“Agostino DP, Mukherjee P. Metabolic therapy: a new paradigm for managing malignant brain cancer. Cancer Lett. 2015; 356:289-300.

26. Klement RJ. Restricting carbohydrates to fight head and neck cancer-is this realistic? Cancer Biol Med. 2014; 11:145-161.

27. Klement RJ, Champ CE. Calories, carbohydrates, and cancer therapy with radiation: exploiting the five R's through dietary manipulation. Cancer Metastasis Rev. 2014; 33:217-229.

28. Champ CE, Palmer JD, Volek JS, Werner-Wasik M, Andrews DW, Evans JJ, Glass J, Kim L, Shi W. Targeting metabolism with a ketogenic diet during the treatment of glioblastoma multiforme. J Neurooncol. 2014; 117:125-131.

29. Nebeling LC, Miraldi F, Shurin SB, Lerner E. Effects of a ketogenic diet on tumor metabolism and nutritional status 
in pediatric oncology patients: two case reports. J Am Coll Nutr. 1995; 14:202-208.

30. Rossi-Fanelli F, Franchi F, Mulieri M, Cangiano C, Cascino A, Ceci F, Muscaritoli M, Seminara P, Bonomo L. Effect of energy substrate manipulation on tumour cell proliferation in parenterally fed cancer patients. Clin Nutr. 1991; 10:228-232.

31. Rieger J, Bahr O, Maurer GD, Hattingen E, Franz K, Brucker D, Walenta S, Kammerer U, Coy JF, Weller M, Steinbach JP. ERGO: a pilot study of ketogenic diet in recurrent glioblastoma. Int J Oncol. 2014; 44:1843-1852.

32. Fearon KC, Borland W, Preston T, Tisdale MJ, Shenkin A, Calman KC. Cancer cachexia: influence of systemic ketosis on substrate levels and nitrogen metabolism. Am J Clin Nutr. 1988; 47:42-48.

33. Morscher RJ, Aminzadeh-Gohari S, Feichtinger RG, Mayr JA, Lang R, Neureiter D, Sperl W, Kofler B. Inhibition of Neuroblastoma Tumor Growth by Ketogenic Diet and/or Calorie Restriction in a CD1-Nu Mouse Model. PLoS One. 2015; 10:e129802.

34. Neal EG, Chaffe H, Schwartz RH, Lawson MS, Edwards N, Fitzsimmons G, Whitney A, Cross JH. A randomized trial of classical and medium-chain triglyceride ketogenic diets in the treatment of childhood epilepsy. Epilepsia. 2009; 50:1109-1117.

35. Fang JW, Lau JY, Wu PC, Lai CL. Fulminant hepatic failure in nonmetastatic renal cell carcinoma. Dig Dis Sci. 1992; 37:474-477.

36. Kranidiotis GP, Voidonikola PT, Dimopoulos MK, AnastasiouNana MI. Stauffer's syndrome as a prominent manifestation of renal cancer: a case report. Cases J. 2009; 2:49.

37. Blay JY, Rossi JF, Wijdenes J, Menetrier-Caux C, Schemann S, Negrier S, Philip T, Favrot M. Role of interleukin-6 in the paraneoplastic inflammatory syndrome associated with renalcell carcinoma. Int J Cancer. 1997; 72:424-430.

38. Altundag O, Altundag K, Gunduz E. Interleukin-6 and $\mathrm{C}$-reactive protein in metastatic renal cell carcinoma. J Clin Oncol. 2005; 23:1044.

39. Gogusev J, Augusti M, Chretien Y, Droz D. Interleukin-6 and TNF alpha production in human renal cell carcinoma. Kidney Int. 1993; 44:585-592.

40. Rego Costa AC, Rosado EL, Soares-Mota M. Influence of the dietary intake of medium chain triglycerides on body composition, energy expenditure and satiety: a systematic review. Nutr Hosp. 2012; 27:103-108.

41. Thompson D, Pepys MB, Wood SP. The physiological structure of human C-reactive protein and its complex with phosphocholine. Structure. 1999; 7:169-177.

42. Woolf EC, Scheck AC. The ketogenic diet for the treatment of malignant glioma. J Lipid Res. 2015; 56:5-10.

43. Tisdale MJ, Brennan RA, Fearon KC. Reduction of weight loss and tumour size in a cachexia model by a high fat diet. Br J Cancer. 1987; 56:39-43.

44. Tisdale MJ, Brennan RA. A comparison of long-chain triglycerides and medium-chain triglycerides on weight loss and tumour size in a cachexia model. Br J Cancer. 1988; 58:580-583.

45. Gullett NP, Mazurak VC, Hebbar G, Ziegler TR. Nutritional interventions for cancer-induced cachexia. Curr Probl Cancer. 2011; 35:58-90.

46. Aoyagi T, Terracina KP, Raza A, Matsubara H, Takabe K. Cancer cachexia, mechanism and treatment. World J Gastrointest Oncol. 2015; 7:17-29.

47. Neal EG, Cross JH. Efficacy of dietary treatments for epilepsy. J Hum Nutr Diet. 2010; 23:113-119.

48. Patel A, Pyzik PL, Turner Z, Rubenstein JE, Kossoff EH. Long-term outcomes of children treated with the ketogenic diet in the past. Epilepsia. 2010; 51:1277-1282.

49. De Giorgis V, Veggiotti P. GLUT1 deficiency syndrome 2013: current state of the art. Seizure. 2013; 22:803-811.

50. Wexler ID, Hemalatha SG, McConnell J, Buist NR, Dahl HH, Berry SA, Cederbaum SD, Patel MS, Kerr DS. Outcome of pyruvate dehydrogenase deficiency treated with ketogenic diets. Studies in patients with identical mutations. Neurology. 1997; 49:1655-1661.

51. Klepper J. GLUT1 deficiency syndrome in clinical practice. Epilepsy Res. 2012; 100:272-277.

52. Pretto F, Ghilardi C, Moschetta M, Bassi A, Rovida A, Scarlato V, Talamini L, Fiordaliso F, Bisighini C, Damia G, Bani MR, Piccirillo R, Giavazzi R. Sunitinib prevents cachexia and prolongs survival of mice bearing renal cancer by restraining STAT3 and MuRF-1 activation in muscle. Oncotarget. 2015; 6:3043-3054. https://doi.org/10.18632/ oncotarget.2812.

53. Moreira DM, Gershman B, Lohse CM, Boorjian SA, Cheville JC, Leibovich BC, Thompson RH. Paraneoplastic syndromes are associated with adverse prognosis among patients with renal cell carcinoma undergoing nephrectomy. World J Urol. 2016; 34:1465-1472.

54. Palapattu GS, Kristo B, Rajfer J. Paraneoplastic syndromes in urologic malignancy: the many faces of renal cell carcinoma. Rev Urol. 2002; 4:163-170.

55. Rota Scalabrini D, Caravelli D, Carnevale Schianca F, D‘Ambrosio L, Tolomeo F, Boccone P, Manca A, De Rosa G, Nuzzo A, Aglietta M, Grignani G. Complete remission of paraneoplastic vanishing bile duct syndrome after the successful treatment of Hodgkin's lymphoma: a case report and review of the literature. BMC Res Notes. 2014; 7:529.

56. Hoegholm A, Kristensen KS, Madsen NH, Svendsen TL. White coat hypertension diagnosed by 24-h ambulatory monitoring. Examination of 159 newly diagnosed hypertensive patients. Am J Hypertens. 1992; 5:64-70.

57. Bisagni G, Boni C, Fornaciari G, Gherlinzoni F. Soft tissues sarcoma with acute paraneoplastic hepatic dysfunction: case report. Tumori. 1996; 82:499-501.

58. Sharara AI, Panella TJ, Fitz JG. Paraneoplastic hepatopathy associated with soft tissue sarcoma. Gastroenterology. 1992; 103:330-332. 
59. Malnick S, Melzer E, Sokolowski N, Basevitz A. The involvement of the liver in systemic diseases. J Clin Gastroenterol. 2008; 42:69-80.

60. Pailla K, Lim SK, De Bandt JP, Aussel C, Giboudeau J, Troupel S, Cynober L, Blonde-Cynober F. TNF-alpha and IL-6 synergistically inhibit ketogenesis from fatty acids and alpha-ketoisocaproate in isolated rat hepatocytes. JPEN J Parenter Enteral Nutr. 1998; 22:286-290.

61. Beylot M, Vidal H, Mithieux G, Odeon M, Martin C. Inhibition of hepatic ketogenesis by tumor necrosis factoralpha in rats. Am J Physiol. 1992; 263:E897-902.

62. Mauer J, Denson JL, Bruning JC. Versatile functions for IL-6 in metabolism and cancer. Trends Immunol. 2015; 36:92-101.

63. Abella V, Scotece M, Conde J, Pino J, Gonzalez-Gay MA, Gomez-Reino JJ, Mera A, Lago F, Gomez R, Gualillo O. Leptin in the interplay of inflammation, metabolism and immune system disorders. Nat Rev Rheumatol. 2017; 13:100-109.

64. Feichtinger RG, Pétervári E, Zopf M, Vidali S, AminzadehGohari S, Mayr JA, Kofler B, Balaskó M. Effects of alpha-melanocyte-stimulating hormone on mitochondrial energy metabolism in rats of different age-groups. Neuropeptides. 2017; 64:123-30. http://dx.doi.org/10.1016/j. npep.2016.08.009.

65. Vergoni AV, Bertolini A, Wikberg JE, Schioth HB. Corticotropin-releasing factor (CRF) induced anorexia is not influenced by a melanocortin 4 receptor blockage. Peptides. 1999; 20:509-513.

66. Anderberg RH, Richard JE, Eerola K, López-Ferreras L, Banke E, Hansson C, Nissbrandt H, Berqquist F, Gribble FM, Reimann F, Wernstedt Asterholm I, Lamy CM, Skibicka KP. Glucagon-Like Peptide 1 and Its Analogs Act in the Dorsal Raphe and Modulate Central Serotonin to Reduce Appetite and Body Weight. Diabetes. 2017; 66:1062-73. https://doi.org/10.2337/db16-0755.

67. Langhans W, Hrupka B. Interleukins and tumor necrosis factor as inhibitors of food intake. Neuropeptides. 1999; $33: 415-424$

68. Konaka H. Editorial Comment to Metastasectomy for metastatic renal cell carcinoma in the era of modern systemic treatment: C-reactive protein is an independent predictor of overall survival. Int J Urol. 2016; 23:922. https://doi.org/10.1111/iju.13194.

69. Falkensammer CE, Thurnher M, Leonhartsberger N, Ramoner R. C-reactive protein is a strong predictor for anaemia in renal cell carcinoma: role of IL-6 in overall survival. BJU Int. 2011; 107:1893-1898.

70. Geng S, Zhu W, Xie C, Li X, Wu J, Liang Z, Xie W, Zhu J, Huang C, Zhu M, Wu R, Zhong C. Medium-chain triglyceride ameliorates insulin resistance and inflammation in high fat diet-induced obese mice. Eur J Nutr. 2016; 55:931-940.
71. Papada E, Kaliora AC, Gioxari A, Papalois A, Forbes A. Anti-inflammatory effect of elemental diets with different fat composition in experimental colitis. Br J Nutr. 2014; 111:1213-1220.

72. Youm YH, Nguyen KY, Grant RW, Goldberg EL, Bodogai M, Kim D, D’Agostino D, Planavsky N, Lupfer C, Kanneganti TD, Kang S, Horvath TL, Fahmy TM, et al. The ketone metabolite beta-hydroxybutyrate blocks NLRP3 inflammasome-mediated inflammatory disease. Nat Med. 2015; 21:263-269.

73. Sharma U, Pal D, Prasad R. Alkaline phosphatase: an overview. Indian J Clin Biochem. 2014; 29:269-278.

74. Calvaruso V, Craxi A. Implication of normal liver enzymes in liver disease. J Viral Hepat. 2009; 16:529-536.

75. Johnston DE. Special considerations in interpreting liver function tests. Am Fam Physician. 1999; 59:2223-2230.

76. Liskiewicz AD, Kasprowska D, Wojakowska A, Polanski K, Lewin-Kowalik J, Kotulska K, Jedrzejowska-Szypulka H. Long-term High Fat Ketogenic Diet Promotes Renal Tumor Growth in a Rat Model of Tuberous Sclerosis. Sci Rep. 2016; 6:21807.

77. Xia S, Lin R, Jin L, Zhao L, Kang HB, Pan Y, Liu S, Qian G, Qian Z, Konstantakou E, Zhang B, Dong JT, Chung YR, et al. Prevention of Dietary-Fat-Fueled Ketogenesis Attenuates BRAF V600E Tumor Growth. Cell Metab. 2017; 25:358-373.

78. Tan-Shalaby JL, Carrick J, Edinger K, Genovese D, Liman AD, Passero VA, Shah RB. Modified Atkins diet in advanced malignancies - final results of a safety and feasibility trial within the Veterans Affairs Pittsburgh Healthcare System. Nutr Metab (Lond). 2016; 13:52.

79. Shinojima T, Oya M, Takayanagi A, Mizuno R, Shimizu N, Murai M. Renal cancer cells lacking hypoxia inducible factor (HIF)-1alpha expression maintain vascular endothelial growth factor expression through HIF-2alpha. Carcinogenesis. 2007; 28:529-536.

80. Feldman A, Eder SK, Felder TK, Kedenko L, Paulweber B, Stadlmayr A, Huber-Schonauer U, Niederseer D, Stickel F, Auer S, Haschke-Becher E, Patsch W, Datz C, et al. Clinical and Metabolic Characterization of Lean Caucasian Subjects With Non-alcoholic Fatty Liver. Am J Gastroenterol. 2017; 112:102-110.

81. Zimmermann FA, Mayr JA, Neureiter D, Feichtinger R, Alinger B, Jones ND, Eder W, Sperl W, Kofler B. Lack of complex I is associated with oncocytic thyroid tumours. $\mathrm{Br}$ J Cancer. 2009; 100:1434-1437. 